\title{
LENGUAJE RITUAL SIN RITUAL ${ }^{1}$
}

\author{
JoHN B. HAVILAND
}

Reed College

Son las doce del dra del Viemes Santo, en el pueblo Tzotzil de Nabenchauk, "La Laguna del Rayo," en los Altos de Chiapas. Un sol brillante ilumina las paredes de la iglesia de Jch'ul-me'tik $\mathrm{Va}$ lalupa - la Virgen de Guadalupe - donde el pueblo se ha reunido para acompañar a los ch'ul moletik - los Ancianos Sagradosque cumplen con sus deberes tradicionales. El pueblo canta en la oscuridad de la iglesia, impregnada de olor a incienso, juncia, rosas, geranios, orquifdeas del bosque, y a humo de cientos de velas; y los moletik lavan la figura de Cristo con agua de flores, lo visten con su ropa nueva, lo suben a la Cruz de cuatro metros, donde lo fijan con clavos decorados con listones de colores. Mientras el pueblo llora, arrodillado frente al Cristo crucificado, los moletik salen al sol para comparir sus botellas de pox, y pronunciar las despedidas rituales que marcan el fin de la Semana Santa. Empezando con el menor, y siguiendo hombre por hombre hasta el mayor, los Ancianos Sagrados se saludan, presentando la mano o la frente, y entonando coplas en lenguaje ritual. Las frases de despedida y gratitud se entremezclan en una corriente de palabras.

1 Una versión de esta ponencia se presentó en el l Coloquio Mauricio Swadesh, 5 a 10 de octubre de 1987, México, D.F. Agradezco a Lourdes de León, Robert Laughlin, William Hanks, Michael Moerman, John Gumperz, y Keith Basso sus comentarios, y a la Harry Frank Guggenheim Foundation su apoyo en la investigación. 


\section{(l) Rezo de los ch'ul moletik para la Semana Santa}

(i) Yos, kumpare,

Dios, compadre

Laj no me li jset' e // laj no me li jutebe

Así se termina el poquito // así se termina el pedacito

(ii) Laj ti tzobolotike /I

Terminamos de reunimos//

Laj ti lotolotike.

Terminamos de juntarnos.

(iii) Ta yalemal yok I/ ta yalemal sk'ob.

Donde se baja su pie // donde se baja su mano.

(iv) Xchi'uk li ch'ul jmanvanej /I

con el sagrado comprador de almas //

Li ch'ul jtojvanej.

el sagrado pagador de almas.

Los rezos, asf como la conducta de los especialistas rituales, tienen una estructura fija — una estructura que a la vez presupone y refleja el contexto. Además, las imágenes de las frases pareadas - las que voy a llamar "dobletes rituales"- captan los aspectos centrales del ritual mismo: la humildad de las ofrendas (jset ' // juteb "poquito, pedacito"), la reunion (tzobol // lotol "reunido, junto") de los oficiales y el pueblo, y el servicio (ta yolon yok // ta yolon sk'ob "bajo el pie, bajo la mano") del santo (sobre todo, el Santo Entierro, jmanvanej //jtojvanej, "el comprador o pagador de almas").

Estos dobletes ubicuos han fascinado a los estudiosos de la literatura mesoamericana, así como a los antropologos. Según ellos, estas construcciones paralelas representan no sólo la poesía indígena, sino también la cristalización verbal de los elementos de una tradición cultural, de una gran antigüedad. Por su forma, sugieren imágenes "estereoscópicas." 2 Es más, entre los tzotziles mismos, los dobletes del rezo formal, sea de curanderos u oficiales religio-

2 Ver James Fox, "Our ancestors spoke in pairs," en Richard Bauman y Joel Sherzer (eds.), Explorations in the ethnography of speaking. London, 1974, pp. 65-85. 
sos, encapsulan los conceptos centrales de la religión o la vida cultural, y al mismo tiempo simbolizan metonímicamente el conocimiènto característico de estos especialistas de la sociedad zinacanteca.

(2) Rezo de curación ${ }^{3}$

(i) $c h$ 'ul toj II ch'ul kantela
pino sagrado, vela sagrada.
(ii) li' ta jlikele /I l' ta jr'abele

Aqui en un momento, aquí en un instante.

(iii) chachoti'o II chavutz'i o siempre

te sentarás para siempre, se te doblaran (las rodillas) para

(iv) ta ti' sna I/ ta ti'sk' uleb

en la entrada de la casa, en la entrada del lugar de la riqueza

(v) t avalab II .. t anich'nabe de tu nifio, tu descendiente.

(vi) kajual mi Seffor.

Un rezo como el del ejemplo (2) incorpora los elementos del codigo convencional de la medicina tradicional. Un $j$ 'ilol, "vidente' o curandero zinacanteco, no se refiere a las velas - su herramienta principal de la curación- con un término sencillo. Les dice ch'ul toj 'pino sagrado' (el árbol del cual se hacfan las antorchas) // ch'ul kantela 'vela sagrada' - la concatenación de una imagen antigua con un prestamo arcaico, dando al objeto un carácter especial a través de una expresión arcana. El hogar del enfermo, y la cruz que guarda su entrada, vuelven a ser, en el lenguaje ritual, sna "su casa" // sk' uleb "el lugar de su tesoro." El paciente mismo se convierte en avalab "tu niffo" // anich' nab "tu descendiente," que son términos de parentesco que ya no se usan en el dialecto cotidiano, pero que enfatizan los enlaces relacionales, cuasi-geneologicos, que unen a un mortal con los dioses ancestrales que 10 cuidan.

${ }^{3}$ Mol Xun Vaskis, Nabenchauk, 14 de febrero de 1976. 
Aunque no es posible demostrarlo con detalle aqui, este código de dobletes tiene otros aspectos bien estructurados. En primer lugar, también existen construcciones tripartitas-tripletes. Además, existe una estructura intema: los dobletes frecuentemente se pueden dividir en dos partes, con un "preludio" que se combina con varias parejas de "finales", entre los cuales el orden está fijo. Así también, la generatividad de la lengua invade el campo del ritual: la morfologfa del Tzotzil permite que un sólo par de raf́ces evoque su imagen convencional en múltiples contextos morfo-sintácticos. En rezos y canciones uno se refiere a las ocasiones rituales por medio de un doblete que incorpora las rafces $t z o b$ "reunir" // lot "juntar." Estas rafces aparecen en forma de adjetivos estativos (como en (lii)), para decir "estar reunidos ritualmente," pero también como sustantivos locativos - zoblebal // lotlebal "lugar donde se reúne, donde se junta"- es decir, "lugar ritual." Saber rezar requiere un repertorio amplio de tales imágenes estereoscópicas, tanto como un conocimiento de los procesos generativos que producen las formas y que las armonizan con sus contextos apropiados. Aquí el uso creativo del lenguaje se extiende a la creación del ritual mismo, y a los parámetros de la interacción social.

Existen criterios socio-culturales en el género ritual también. El habla ritual pertenece a los especialistas. Según las creencias, un j'ilol no aprende a rezar, sino que recibe este don de los antepasados en un suefio, igual que los músicos y los totilme 'iletik - "los padres madres" o consejeros rituales - cuyas habilidades lingüísticas también provienen de fuentes sobrenaturales. Esta inspiración divina implica, por lo tanto, que los especialistas rituales tratan de acomodar sus palabras a la ocasión, pero que su habla sólo puede aproximarse a lo ideal. Los no-especialistas pueden lograr un conocimiento limitado del género, sin esperar una fluidez total. Hasta en los rituales más mundanos, un zinacanteco común y corriente pedirá a algún experto instrucciones detalladas sobre las frases y expresiones correctas para las etapas de una ceremonia.

Los curanderos, los músicos, y hasta los antropologos nos han dado esta visión muy estructurada, que separa el lenguaje de do- 
bletes del lenguaje común y no-paralelo, y por lo tanto, que divide los contextos rituales de los contextos cotidianos. Sin embargo, en este trabajo, quisiera dar unos pasos cautelosos que nos puedan sacar de esta perspectiva tal vez demasiado pura. Cuento con la inspiracion del Dr. Swadesh, en la forma de su colaboracion famosa con Edward Sapir en la publicación de algunos mitos y textos en Nootka. ${ }^{4}$ Apuntare, también, algunas ideas de Mikhail Bakhtin sobre el genero, ${ }^{5}$ ideas que Sapir y Swadesh anticiparon implícitamente.

Los textos en Nootka combinan lo que los autores llamaban mitos y leyendas con textos etnográficos, cuentos, y otras narrátivas. En los términos de Bakhtin, se trata de una colección de géneros primarios combinados con géneros secundarios, los que incorporan elementos de Ios primarios: asi que una narrativa historica puede incluir fragmentos de mitos, de cantos, de leyendas, de conversaciones naturales, o lo que sea. Además, Swadesh nos dice que

estas narrativas expresan la base cuasi-histórica y filosofica de la práctica shamanística y ceremonial indígena. ${ }^{6}$

El combinar textos cotidianos con cuentos mitologicos representa una hipotesis implícita: que los géneros más fijos y culturamente determinados también fertilizan, como las alusiones literarias, los demás "textos" etnográficos - tomando el término "texto" en un sentido amplio. Otra lección de Bakhtin, también prevista implícitamente por Swadesh y Sapir, pone en duda la idea de una literatura, o de cualquier género del habla, separado del contexto social, interactivo, y t́picamente "dialogico" (sino "multi-16-

4 Ver E. Sapir y M. Swadesh, Nootka texts, tales and ethnological narratives, 1939, y E. Sapir y M. Swadesh, Native accounts of Nootka ethnography, Bloomington, 1955.

5 Ver M. Bakhtin, Speech genres and other late essays, Austin, 1986.

6 .... these narratives embody as it were the cuasi-historical and philosophical basis for native shamanistic and ceremonial practices." Sapir y Swadesh (1955:1) 
gico") de su producción. Desde esta perspectiva, vemos los dobletes en Tzotzil no sólo como elementos atómicos de un código abstracto, sino como recursos expresivos; y entendemos el paralelismo no sólo en sus contextos presupuestos -es decir, en contextos rituales- sino en su carácter creativo en la vida social. Me interesa, entonces, extender el estudio del tzotzil ritual a los contextos no-rituales por medio de una excursión correspondiente a la de los géneros secundarios del habla zinacanteca y la conversación natural.

En este caso, la semilla etnografica se sembro una tarde en Semana Santa hace unos afios. Estaba de regreso en el pueblo de Nabenchauk, después de casi tres anfos de no haberlo visitado. Mientras almorzaba tortillas recién hechas y hojas de napux, una amiga me contaba los acontecimientos $\longrightarrow$ bien, los desastresde los ultimos afios: muertes, peleas, incendios, matrimonios rotos, brujos, enfermedades, sequías, y alzas. Su relato era un ejemplo de lo que se llama lo il no ox "una plática nada más." Élla no era ni curandera ni partera, pero me di cuenta, poco a poco, del hecho incontrovertible de que mi interlocutora me hablaba en un tzotzil elegante y emotivo, reforzado con dobletes. Usaba las mismas frases paralelas que caracterizan el lenguaje ritual del rezo del curandero, 0 las canciones religiosas que acompafian los bailes de las autoridades, pero aquí sólo acompafiaban mi comida humilde y las danzas de las gallinas en el patio.

Así empecé un estudio más amplio de los usos del lenguaje del ritual en contextos cotidianos, no-rituales. No vóy a detallar aquí los acertijos conceptuales que implica esta formulación del problema. Además, sólo puedo mencionar brevemente algunos resultados principales de esta investigación. Por ejemplo, parece que las construcciones paralelas se relacionan no solo con contextos pre-determinados, sino también con contextos donde un hablante quiere asumir una autoridad especial, donde el lenguaje ritual le presta un poder implícito o la impresión de veracidad, o donde el momento del paralelismo produce un efecto organizacional en la interaccion. Asimismo, he investigado los límites del conocimien- 
to - del competence - que tienen los zinacantecos para utilizar el género de dobletes; la variación que existe en estas habilidades entre jovenes y ancianos.

En este trabajo me interesa concentrarme en el uso de los dobletes en el Tzotzil zinacanteco como vehículo afectivo. Mi argumento tiene tres partes: (l) que el habla paralela expresa un estado cargado de emocion en el hablante; (2) que por lo tanto, el uso de los dobletes tzotziles también puede evocar una carga emocional; y (3) que, en consecuencia, el uso de los dobletes en los géneros secundarios es un mecanismo sutil y poderoso para representar los estados emocionales. Me aprovecho de algunos ejemplos del tzotzil natural, que demuestran la riqueza de la lengua como medio expresivo.

Entre las categorfas indígenas del habla, existe la idea de $k^{\prime} a k^{\prime} a l$ $\boldsymbol{k}$ 'op 'palabras ardientes'-palabras cargadas de enojo, rabia, pesar, u otra emoción profunda. Según las ideas zinacantecas, una persona afligida con tales emociones característicamente puede producir un torrente de palabras, una ola de emoción verbal que integra construcciones paralelas. Este producto verbal se considera el resultado de una condición de fuego interno, $k^{\prime} a k^{\prime} a l$ ' $o$ 'onil "el corazón ardiente", y es, por lo tanto, evidencia implícita, o más bien, un síntoma definitivo del caos emocional. Una persona que ha sufrido una injusticia, que guarda resentimiento u odio en el corazon, se considera capaz de enfermar a otros; un método para lograrlo es a través de un rezo especial: -ok' ita -ba "lamentarse" u -ok' ita kajvaltik "lamentar a Nuestro Señor." Se dirige este rezo a los dioses ancestrales, que producen una enfermedad que se llama ok'itabil chamel "enfermedad producida por lamentarse." Estas denuncias rituales son necesariamente privadas, pero su tono se puede inferir de las denuncias estilizadas que se producen en algunos contextos públicos: en el cabildo, o de vez en cuando en la calle. Según Laughlin, estas denuncias "invariablemente" emplean "los dobletes tradicionales."7 En su diccionario tzotzil, Laughlin presenta algunas muestras, que se ven en el ejemplo (3).

7 R. Laughlin, The great Tzotzil dictionary of San Lorenzo Zinacantan, Washington D.C., 1975, p. 28. 
(3) Dobletes para la denuncia (Laughlin, 1975) ${ }^{8}$

(a) 'abol jba 'uk //'utz' utz' jba 'uk. Yo tambien sufro, yo tambien estoy en la miseria.

(b) ta xvinaj I/ ta $x$ 'osilaj; ti smule I/ ti skolo 'e. Se va a aparecer, se va a ver en la tierra, su pecado, su maldad.

(c) jk'u 'ultasojot II jpak' altasojot; ti l ach'ie II ti l ak'opoje. Yo te he vestido, yo te he cubierto, para que crezcas, para que hables.

(d) hablando de una familia que, después de haberle aceptado al novio el pago por la novia, no suelta a la muchacha; jun yo 'on ta slekin // ta xutzin; ti j-set'e I/ ti jutebe. Muy contentos disfrutan, gozan, del poquito, del pedacito.

(e) mujer que niega una aventura amorosa; mu xu'xkik' ti jpak' ale I/ $t$ jnochole. No puedo casarme con el bajo, con el infame.

(f) persona que se queja, en el cabildo, del comportamiento de su esposa u otra persona; $t$ xich' jambel sk' exlal // snamal. Su vergüenza, su mortificación, debe de ser descubierto.

(g) los padres de una muchacha que se ha fugado; nupulik $x a$ /I tz'ajalik $x a$; jun xa yo 'onik; tze 'ejik xa /l lo 'ilik xa; yan li vo 'one mu xa bu yilojon yilel. Ya están casados, ya están unidos, ya están contentos, ya se ríen, ya platican, pero parece que a mí no me han visto nunca. ${ }^{9}$

(h) persona que acusa o reta a un brujo públicamente; tik on $t$ achak // tik' on $t$ avat. Clávame en tu culo, clávame en tu pene (o) vagina.

${ }^{8} \mathrm{He}$ alterado la ortografia.

9 El ejemplo viene de Laughlin (1975:260). Los dobletes se alteman con fragmentos no-paralelos; pero la estructura total demuestra un paralelismo complejo de la siguiente forma:

ellos - la pareja:

están casados//unidos

están contentos

riendo//platicando

pero yo (el papa) estoy abandonado 
(i) mu 'yuk jvinik // mu 'yuk kajmul. No tengo hombre, no tengo amante. (La raíz mul significa 'pecado.')

El sabor de los dobletes, y las escenas sugeridas, evocan los contextos típicos en los que se encontrarfan estas expresiones. Podemos oir las palabras en las bocas de los sufridos: oprimidos, olvidados, rechazados, maltratados, 0 acusados injustamente. Y podemos ver, detrás de estas palabras, a los adversarios: hijos ingratos o haraganes, vecinos orgullosos, parientes codiciosos, esposos infieles, $y$ brujos peligrosos.

Estas denuncias no se limitan al cabildo o a la cueva. Mi ámiga, esa tarde de Sẹmana Santa, me presentó una, y he transcrito otra, en el ejemplo (4).

(4) Un monólogo sobre la desgracia ${ }^{10}$

1 pero bweno mu $k$ usi

Pero bueno, no hay remedio.

2 chibatikbtik ta Jteklum che'e // chba jk'opontikotik Presidente //

Vamos a Zinacantán, vamos a hablarle al presidente

3 chba lok' uk 'akta noxtok

Va a salir un acta, también

4 mi mu xa ssa' $k$ 'op bak' in //

mu ma xa $k^{\prime} u$ spas bak' in

para que ya no busque pleitos //

que no haga nada después.

5 mas mijor

sería mejor

6 lek mi chkom ta 'akwerto jchi'uk Mikele llegar a un acuerdo con Miguel.

7 timi xtal k'opojuk si viene a hablar (amistosamente).

8 yan timi mu xisk'opon // mi kapeme de otra forma, si no me habla // si está enojado.

${ }^{10} \mathrm{PV}$, de un casette grabado en agosto de 1977. 
9 yech'o k'u ma xi ta jk'opon jbatikótik Así, ¿cómo vamos a hablarnos?

10 mi kapem $k$ ' $u$ cha'al ti vo'ne 'onoxe si sigue enojado como siempre estaba antes.

11 komo yo'onuk 'onox chismil // como siempre tenía ganas de matarme

12 yo'onuk 'onox chis- ... ak'u yak' ti marinae siempre tenía ganas de...

de que me iba a disparar con escopeta. ${ }^{11}$

13 pero muk' bu licham yu'un 'un Pero yo nunca me morí.

14 ora lavi une tzmala tzmala chicham // tzmala chilaj $\mathrm{Y}$ ahora sigue esperando a que me muera// que me acabe

15 istuch' ti kantelaetike // chonvan ta balamil, cortó velas // vendió almas al Dueño de la Tierra

$16 x$ chi' $u k$ ti yaj'ilole con su curandero brujo

17 skotol $k$ 'u spas ha hecho todo

18 'ak'o chamikon la // lajikon la ${ }^{12}$ para que me muera // para que me acabe

19 pero bweno tzk' an ti kajvaltike, muk' licham 'un pero gracias a Nuestro Señor, no me he muerto.

Este monologo me lo grabo un compadre zinacanteco y me lo mandó a Australia. En él, me cuenta una serie de catástrofes ocurridas en la familia, sobre todo un pleito bastante grave con su hermano menor, que había regresado al pueblo después de muchos affos de estar fuera, y que provoco una pelea muy violenta sobre la herencia y el terreno familiar. Genéricamente, este fragmento es

$11 \mathrm{P}$ aquí quiere construir un doblete paralelo, que empieza con yo'onuk chismil 'tiene ganas de matarme.' La segunda línea empieza igual: yo'onuk chis-. Pero el renglón se tiene que romper, aparentemente porque $\mathrm{P}$ no encuentra un verbo adecuado para completar la frase. El marco incluye ch- 'aspecto incompletativo,' $i$ - 'primera persona absolutivo,'y $s$ - 'tercera persona ergativo': "él me va a -." La línea se continúa con una construcción no-paralela: ak'u yak' ti marinae '(quiere) que (alguien) use una escopeta (contra mi).'

12 Forma corta del doblete. 
único, porque no se dirigió ni a los antepasados ni a las autoridades, sino a una grabadora. Sin embargo, es un ejemplo muy poderoso del uso de la estructura paralela con motivos expresivos. He indicado con los diagonales dobles las estructuras paralelas en el fragmento; 10 que no se puede representar graficamente es la entonación que típicamente acompaña los dobletes y que también señala el género.

En la línea (4) mi compadre da un ejemplo canónico de un doblete extemporáneo. Inserta dos frases distintas ( $s a^{\prime} k$ ' op "busca pleitos" y pas "hacer" —un pro-verbo neutro) en el mismo marco: mu xa s-bak' in "para que él (el hermano) ya no vaya a más." En la línea (8) mi compadre utiliza dos sinonimos sociales para formar un doblete de "estar enojado" y "no (querer) hablar", que son, en Zinacantán, sintomas equivalentes de una relación social terminada o en mal estado. En la línea (11), mi compadre presenta un catálogo de los delitos y las intenciones malas de su hermano: amenazas, intimidación, brujería - todos moldeados en frases paralelas, aparentemente inventadas espontáneamente.

Parad6jicamente, el uso de los dobletes puede expresar no sólo un estado de emoción fuerte, sino también un control, una reserva, o un autodominio. Cuando la gente se altera y los malos genios pueden escaparse, los dobletes parecen permitir que los enojos salgan al aire sin alborotar demasiado a los combatientes. Los agentes municipales o los ancianos que adjudican peleas, muchas veces formulan sus decisiones y sus opiniones morales en términos paralelos. El efecto es combinar una aparencia de preocupación seria y amonestación con la autoridad sobria y racional, o expresar un enojo controlado por medio de una habla controlada.

(5) Criticando a un hombre que golpea a su mujer ${ }^{13}$

$1 \mathrm{p}$; bweno lak'u' alapoj le'e bueno, esa ropa que traes puesta

${ }^{13}$ Nabenchauk, 26 de abril de 1981. A es el culpable; $P$ es el anciano que está arreglando el caso. En los fragmentos conversacionales, se emplean algu- 
2 mi..mi manbil avak'ojbe mi ja' yabtel= ¿la compraste, o es el trabajo de ella?

$3 \mathrm{a} ;=\mathrm{i}$ 'i ma'uk 'une No, no (yo la compré).

$4 \mathrm{ja}^{\prime}$ chjal ella la tejió.

$5 \mathrm{p}$; va'i 'un para que veas

6 'ati taj ... sba avajnile 'tu primera esposa

$7 \mathrm{mi}$ ja' 'onox yech lak'u' lakom chk le'e ¿ella te dejaba siempre vestido asi?

[

8 a; kere.. ch'abal 'un tot Ay, pues no, señor.

9 mu xu' jnop li k'op= no te voy a decir mentiras.

$11 \mathrm{p}$; va'i 'un, li 'antz 'une Así es que con esta mujer...

12 jalom ata // $\mathrm{j}^{\prime}$ abtel ata has conseguido a una tejedora // una trabajadora

13 K'usi yan chak'an ya'el 'un // ¿Qué otra cosa quieres?II

14 k'usi xa li palta tajmek ¿Qué te hace falta ya?

15 batz'i lok'el xa'ilin // xakap 'un Pero siempre estás enojadol/ tienes rabia.

En el ejemplo (5), un anciano del pueblo está tratando de reconciliar a un hombre con su esposa. Da un argumento para avergonzar al hombre: le recuerda que esta mujer, a diferencia de su esposa anterior, trabaja mucho y teje bien. Cuando llega al final, pone sus conclusiones, en los renglones (11)-(15), en forma paralela,

nos símbolos especiales, los que son: =("latch") indica que dos enunciados se conectan sin pausa; [ y ] entre líneas indican que los enunciados se traslapan. El texto tzotzil aparece en un tipo normal (p. ej. lak'ue), y la traducción española en un tipo enfatizado ( $t u$ ropa). 
con las entonaciones características del lenguaje ritual de la autoridad y del poder.

Mi última observación se relaciona con los géneros secundarios: los cuentos, las narrativas, la representación de la realidad cultural en términos verbales. Cuando los zinacantecos recuentan las escenas emotivas o afectivas, pueden indicar que un protagonista está enojado o alterado poniéndole en la boca palabras enojadas: es decir, dobletes.

Notese primero que el valor pragmático de la forma paralela puede invertirse. Los dobletes, con su asociación con el ritual y la formalidad, pueden resultar en un insulto, una ofensa, por el conflicto entre forma formal y contenido abusivo.

(6) Un intercambio de insultos en la carretera ${ }^{14}$

$3 \mathrm{p} ;=$ chbat ta tuxta $=$ Iba a Tuxtla [para vender duraznos]

$4 \mathrm{c} ; \quad=\mathrm{a}:$.

5 p; “kavron mu xak'exav kavron batz'i: = “ $i$ Cabrón, no tienes vergüenza, cabrón!

6 ="puta tasajo // puta taxux. < "puta tasajo II puta cebolla

7 “lek'o ta chichol // lek'o ta tuix kavron = ";lámelo con tomatilloll lámelo con cebolla, cabrón!"

$8=x$ 'utat la li Maryan Lol 'un= Asi le dijo a Mariano Lol.

En (6), un zinacanteco recuenta una batalla verbal entre miembros de dos partidos opuestos. A uno de estos protagonistas le atribuye una oración en forma paralela con dobletes un tanto oscuros. Se trata de un PANista contra un PRlista, y en Zinacantán el nombre del PAN ha inspirado muchos chistes e insultos culinarios basados en la palabra pan. (En Tzotzil, 'pan' es kaxlan vaj "torti-

${ }^{14}$ De una conversación grabada en Nachij, en agosto de 1978. 
lla castellana" - es decir, "ladina"). Pero en este caso, el líder de la facción PRlista tiene el apodo tasajo (o, en Tzotzil, taxux), lo cual presenta una oportunidad al PANista para explotar su propio juego de palabras. La invectiva sale en forma de dobletes:

puta tasajo / / puta taxux

¡lámelo con tomatillo! / / jámelo con cebolla!

le dice el PANista al PRIista, burlándose del líder de PRI.

(7) Reporte de las quejas de una mujer golpeada ${ }^{15}$

$3 \mathrm{t}$; =ja' taj 'ali:. li' chul yal li 'ali yajnile $=$ Esto es lo que llegó a decir su esposa.

$4 \mathrm{p} ;=\mathrm{aa}$

$5 \mathrm{t} ;$ “'ali 'albon jk'antik // “Queremos que le digas de mi parte II

6 'jch'amun ave jk'antik // "queremos que me prestes la bocall

7 'tzitzbon jk'antik "querernos que me lo castigues

8 "k'u 'onox ti 'animal chismaje // 'animal chiyute “¿por qué me pega tanto? I/ ¿me regaña tanto?

9 “"an timin ta'lo xiya'ie "si ya está harto de mi

10 'stak' tuk' xistak' 'ech'el "derecho me puede echar para fuera

11 "batz'i mu 'onox bu xtal ti. 'ati ${ }^{16}$ jlekile // "no me viene ninguna felicidad/I

12 "mu 'onox bu xtal ti kutzile “no me viene ninguna fortuna.

13 "albon jk'antik ' un “querernos que le digas asi de mi parte

${ }^{15}$ Nabenchauk, 12 de abril de 1981. El discurso indirecto aparece entre comillas, en tzotzil y en español.

${ }^{16} \mathrm{La}$ partícula 'ati, que se usa para llenar una pausa de vacilación, demuestra que el hablante tenía que pensar en un doblete adecuado aquí. 
14 "yu'un batz'i ta xa xicham 'o 'un //

ta xa xilaj 'o "un

"porque de veras ya me estoy muriendo II

me estoy acabando de eso

15 "ti majele // ti "utele."

"de los golpes // del regaño"

16 xi li x'i'on ta ti' na chka'i ja' ba 'ik' le'e

Eso es lo que le decía llorando cuando vino a buscar (al presidente).

Para terminar, véase, en el ejemplo (7), como una zinacanteca recuenta las quejas de una mujer golpeada que llego a buscar la ayuda de una autoridad del pueblo. En construcciones dobles, y a veces triples, en un sólo tumo largo en la conversación, la narradora representa la querella de esta esposa desesperada en el lenguaje estructurado de $o k$ ' ita bail "lamentaciones." Con frases paralelas, la mujer dramatizada pide la ayuda de la autoridad (líneas (7) 5-7):

lo que queremos es:

que le digas de mi parte //

que me prestes la boca //

que lo castigues para mí

Se queja amargamente de las múltiples formas en que su marido la maltrata:

¿Porqué me pega tanto? //̨me regaña tanto? (8) no me viene ninguna felicidad// ninguna fortuna (11-12)

ya me estoy muriendo// me estoy acabando (14)

de golpes // de regaño (15)

El paralelismo se vuelve un índice del estado emocional de la protagonista a través de esta habla "indirecta" o "reportada."

El habla, y el juego complejo entre los géneros, su realización lingüística, y los "textos" correspondientes resultan ser -como siempre- recursos centrales para la descripción etnográfica. Re- 
gresamos, así, a la moraleja de los textos Nootka de Swadesh: los textos son lentes que nos dan una visión indirecta de la cultura Nootka. Los textos naturales del habla, de manera semejante, proveen una entrada indirecta a la realidad social.

El lenguaje ritual de Zinacantán nos recuerda, además, la conexión intima entre el lenguaje y el poder: que el capital lingüísti$\operatorname{co}^{17}$ es también capital sociopolítico; que el habla del que ordena puede ordenar, que las palabras de las autoridades son autoritativas; y que la lengua del poderoso tiene poder. Las imágenes metalingüísticas del tzotzil ritual mismo nos enseñan algo parecido. Mi compadre Petul Vaskis, como sus antepasados, usa los dobletes formales del batz' $i k^{\prime}$ op "la lengua verdadera" para expresar el contraste importantísimo entre

i'onel I/ a 'onel

"parloteo y tartamudeo"

y

$k^{\prime}$ op // rason

"palabras y razón."

Ojalá que pudiéramos distinguir las dos cosas.

17 Ver Pierre Bourdieu, ¿Qué significa hablar? Economia de los intercambios lingülisticos, Madrid: AKAL. 